\title{
The Utilization of E-Learning and Artificial Intelligence in the Development of Education System in Indonesia
}

\author{
Rissia Priyahita \\ Department of Communication \\ Universitas Indonesia \\ Jakarta, Indonesia \\ rissiapriyahita@yahoo.com
}

\begin{abstract}
Technology movement creates progressive impacts towards the development of communication network, computer, and the Internet. An innovation that is known as Artificial Intelligence (AI) is one of many products. The usage of AI technology is predicted to expand globally, including in Indonesia. This statement is supported by an Accenture study that states about $87 \%$ of Indonesian respondents recognize AI technology capabilities in supporting interactive learning, including e-Learning. The influence of AI technology on improving the effectiveness of e-Learning concepts enables integration into the advancement of the education system in Indonesia. This study aims to explore the potential and impact of applying AI technology in e-Learning, and the readiness of various factors that influence the education system and Information and Communication Technology (ICT) in Indonesia. The discussion is based on secondary data and comprehensive observations of the prevailing learning structure.
\end{abstract}

Keywords-e-Learning, Artificial Intelligence, Information and Communication Technology, Indonesia

\section{INTRODUCTION}

The flow of globalization plays an important role in the dynamics that include developments in the field of information and communication technology in Indonesia. Along with these developments, computer systems and networks have also increased, making the Internet's role as a vital information and communication media. The existence of the Internet is no longer just an option but an important part of everyday human life. Along with the changing times and needs, the challenges in the education sector are increasingly greater to prepare students who are able to compete in the global arena. However, with increasing challenges, the world of education in Indonesia still has many obstacles.

Education in Indonesia faces several major problems related to access and quality. Only about half of eligible children are enrolled at the junior secondary level and only one third at the senior secondary level. Regarding quality, most students fail to meet the passing grade scores in various subjects at all levels on the final school exam. Information and communication technology is seen as a potential contributor to solutions to this problem. The success of information technology depends on the availability of the right infrastructure. In 2017, 104.96 million people accessed the internet in Indonesia. This figure is projected to grow to 133.39 million in 2021. Other statistics show that information and communication technology infrastructure is less extensive compared to neighboring countries such as Singapore, Malaysia, and Thailand. In addition, the cost of internet access is still relatively expensive in Indonesia.

The application of e-Learning in Indonesian education can be seen as a complement or substitute for the traditional teaching-learning process. According to Oemar Hamalik, learning media are tools, methods and techniques used in order to make communication and interaction more effective between teachers and students in the education and teaching process in schools. E-Learning, in this case, is one form of learning media that can facilitate and optimize the teachinglearning process in the education system in Indonesia. Republic of Indonesia Law No. 20 of 2003 concerning the National Education System, Article 31 states: 1) Distance education functions to provide educational services to community groups who cannot attend face-to-face or regular education; 2) distance education is carried out on all lines, levels and types of education; 3 ) distance education is carried out in various forms, modes and scope supported by learning facilities and services as well as an assessment system that ensures the quality of graduates in accordance with national education standards, and; 4) forms of distance education include written education programs, radio, audio or video, television, and computer network-based media. In accordance with the Act, to date there are a number of subjects from High School (SMA) and the Vocational High School (SMK) curriculum that have been developed in the form of e-Learning as a substitute for face-to-face instruction. At the tertiary level of education, most universities in Indonesia have implemented e-Learning, especially as a support for their regular teaching and learning process. In its expansion, the Ministry of National Education has tested Open High Schools in seven districts in six provinces by implementing e-Learning.

In its implementation, there are several obstacles that prevent the further application of e-Learning. First, infrastructure that does not support learning. Of the 267 million people, only 27 million have fixed telephone facilities, a prerequisite for accessing long-distance e-learning facilities. Using a cell phone for an internet connection is not possible because of high costs, and on the other hand Internet customers in Indonesia are limited. Second, in content management. Although the majority of e-learning operators are higher education institutions, there are no standards in their content that do not always reach academic intellectual 
standards. Third, there is no structured and comprehensive coordination in implementing e-Learning. In certain universities, each department establishes its own e-Learning facility without disrupting the efforts of other departments, especially at the national level. Fourth, cultural factors. Communities in Indonesia generally prefer speaking verbally to writing, and prefer to attend teaching and learning activities rather than studying on their own. Therefore, Indonesian students prefer to communicate or interact directly with other students or lecturers rather than communicating in a virtual way as is commonly found in e-Learning.

Seeing this situation, so that the e-Learning system can provide optimal benefits in the long run, currently a more structured and integrated system design is needed, with the use of appropriate technology in order to fulfill its objectives as a learning medium capable of equipping students to compete and remain literate information technology, in a flexible way. One of them is by utilizing Artificial Intelligence (AI), namely artificial intelligence, which can overcome a number of deficiencies in e-Learning and the education system in Indonesia.

\section{DISCUSSION}

\section{A. E-Learning}

One concrete form of using the Internet is a distance learning system that is utilized electronically or called eLearning. e-Learning is part of e-Life, a technological idea related to the life cycle. Based on electronics, e-Life enables humans to carry out daily activities through technology assistance. Internet, satellite, or CD-ROM are some of the various electronic media choices available. Through eLearning, teaching can be delivered at the same time (synchronously) and different (asynchronously).

Perception about e-Learning is divided into 2 (two) types, namely:

- Electronic-based. Learning systems tend to use the concepts of information and communication technology, especially those with electronic backgrounds. Utilization is not based on the Internet alone, but other electronic devices such as films, Over Head Projectors (OHP), video, projectors, and others.

- Internet-based. Slightly different from the previous type, the use of Internet-based e-Learning relies on Internet facilities that are online as the main instrument. The learning system is required to use the Internet. To apply this type, schools or educational institutions must have a computer connected to the Internet. As a result, the level of flexibility in accessing learning material increases because it is not limited by distance, space, and time, and can be done anywhere and anytime.

The dimension of understanding of e-learning extends with the presence of these two perceptions. There is an assumption that learning material, in the e-Learning pattern, does not have to be distributed online or through an Internet connection. Interaction can be done offline via CD / DVD distribution and so on. With e-Learning patterns like this, the development of applications and learning materials that suit your needs becomes easier and can be directly distributed via CD / DVD. The media can be used or used wherever teachers and students are, without first having to look for an internet connection [1].

This understanding is supported by various opinions from experts such as Elliott Masie, Cisco, \& Comellia [2] who argue that e-Learning is a type of learning that can communicate material through electronic media (Internet, Intranet, satellite, TV, CD-ROM). E-Learning does not have to always depend on an Internet connection, bearing in mind the accessibility to the Internet in the world is not yet equitable. This opinion has the support of Martin Jenkins \& Janet Hanson [3]. Both experts assume that e-Learning is a learning process that is facilitated by the use of communication information technology to create an efficiency that is not obtained by traditional learning process models.

The e-Learning learning program was first introduced by the University of Illinois, Urbana-Champaign, in 1990 using a computer-based instruction system, PLATO. The following is a track record of the development of e-Learning from the initial introduction to finally developing into a web-based application that continues to be used (and innovated) to the present, shown in Table 1.

\section{TABLE I. DEVELOPMENT OF E-LEARNING SYSTEMS}

\begin{tabular}{|l|l|}
\hline 1990 & $\begin{array}{l}\text { This year, e-Learning applications appear in the form of } \\
\text { stand-alone PCs or CD-ROMs. The media contains material } \\
\text { in writing or multimedia and uses MOV, MPEG-1, or AVI } \\
\text { formats. Therefore, 1990 was declared as the era of CBT } \\
\text { (Computer-based Training). }\end{array}$ \\
\hline 1994 & $\begin{array}{l}\text { After being well received by the public as a user, CBT began } \\
\text { to be presented in a more attractive form, even through the } \\
\text { mass production process. }\end{array}$ \\
\hline 1997 & $\begin{array}{l}\text { As technology developed, audiences began to associate } \\
\text { themselves with the Internet and the need for fast and } \\
\text { accurate information began to become a primary need. } \\
\text { Distance and location are no longer a barrier to meeting the } \\
\text { needs of using Internet technology. This year marks the rapid } \\
\text { development of the LMS (Learning Management System) } \\
\text { and is a solutive thought to overcome the problem of } \\
\text { interoperability between LMS. The standard forms of LMS } \\
\text { that appear this year are usually from AICC (Airline Industry } \\
\text { CBT Committee), IMS, SCORM, IEEE LOM, and } \\
\text { ARIADNE. }\end{array}$ \\
\hline 1999 & $\begin{array}{l}\text { This year was marked by the LMS transition to a web-based } \\
\text { e-Learning application, beginning with the convergence } \\
\text { between LMS and other media such as news sites, } \\
\text { magazines, or newspapers. Material content, too, becomes } \\
\text { varied with the combination of multimedia and interactive } \\
\text { display. Even so, the choice of data format actually changed } \\
\text { to more standard and smaller size. }\end{array}$ \\
\hline
\end{tabular}

As a contemporary learning pattern, e-Learning has several characteristics that are closely related to electronics and technology:

- Utilizing electronic technology services to accelerate the acquisition of information and facilitate communication between teachers and students.

- Utilizing a computer as an electronic means that facilitates the structure of learning, evaluates the results of learning progress, and meets administrative needs. Material is also obtained through computers, 
considering that computers provide information from various sources of information. Learning material can also be stored in computer files (archives) so that it can be accessed by teachers and students when in need, anywhere and anytime.

- In addition to hardware, the concept of e-Learning also utilizes software such as computer networks (digital networks) to collect learning material which is then studied independently (self-learning materials).

It seems that modern concepts such as e-Learning are not completely separate from traditional learning concepts. According to Siahaan, there are 3 (three) electronic learning functions in traditional learning activities or in the classroom (classroom instruction), namely:

TABLE II. FUNCTION OF E-LEARNING SYSTEMS

\begin{tabular}{|c|c|c|}
\hline Substitute & Complement & Supplement \\
\hline $\begin{array}{l}\text { E-Learning, in the } \\
\text { sense of } \\
\text { 'substitution', is } \\
\text { useful to replace } \\
\text { learning in the } \\
\text { classroom if students } \\
\text { are absent or absent. } \\
\text { In practice, e- } \\
\text { Learning does not } \\
\text { require a face-to- } \\
\text { face process as } \\
\text { always applied in the } \\
\text { classroom. }\end{array}$ & $\begin{array}{l}\text { E-Learning also } \\
\text { works as a } \\
\text { 'complement', in the } \\
\text { sense that learning } \\
\text { material that is not } \\
\text { available or has not } \\
\text { been delivered in } \\
\text { class can be } \\
\text { distributed through } \\
\text { electronic media } \\
\text { such as CDs or flash } \\
\text { disks given to } \\
\text { students and can be } \\
\text { studied and } \\
\text { independently and } \\
\text { flexibly. }\end{array}$ & $\begin{array}{l}\text { In some conditions, } \\
\text { teachers feel the } \\
\text { need for additional } \\
\text { material as a } \\
\text { 'supplement' for } \\
\text { students. Because } \\
\text { traditional learning } \\
\text { systems are limited } \\
\text { by time, teachers can } \\
\text { utilize e-Learning } \\
\text { media that is much } \\
\text { more flexible. } \\
\text { Additional material } \\
\text { can be posted into } \\
\text { electronic media and } \\
\text { then studied by } \\
\text { students at home. }\end{array}$ \\
\hline
\end{tabular}

b. Source:Siahaan [5]

In this sense, e-Learning is useful to facilitate the continued interaction between students and learning material. The teacher or instructor is also given the opportunity to place learning materials and assignments in certain documents on the website or other electronic media for later access by students. The benefits of e-Learning, when discussed in more detail, are divided into several categories and divided according to the point of view of students and institutions (instructors). However, the benefits of e-learning in general will be discussed beforehand:

\section{1) Flexibility}

Learning tools in the e-Learning category free users to choose a time and place to access trips. In addition, the range that is able to be covered is very broad, in contrast to traditional learning which is limited by factors of space or number of students. The e-Learning or online learning room can accommodate large numbers of students without worrying about seating limitations and so on.

\section{2) Accessibility}

One of the main keys in e-Learning is subject matter that is obtained easily and nimbly. Almost similar to traditional learning, e-Learning learning has a curriculum that contains a number of subject matter that must be understood and mastered as a whole by students (even without the help of instructors). Assisted by technological sophistication, these materials can be downloaded and accessed anytime and anywhere without being limited by time or other factors.

\section{3) Independence}

The pattern of e-Learning learning systems gives students the opportunity to take control of learning success. Example: individuals who are already working, but wish to continue their education to a higher level. Due to the main preoccupation with work, the individual cannot attend classes or take part in general lecture activities. E-Learning comes as a solution by providing lecture material online so it does not require the presence of individuals in the classroom. Individuals, or students, are given the freedom to learn and create indicators of success independently.

\section{4) Efficiency (Time and Cost)}

As previously discussed, online learning or e-learning is supported by technological sophistication so that it does not require physical facilities in its application except electronic media (computers, tablets, etc.) and can be done anywhere and anytime. These characteristics certainly have a positive impact in increasing cost efficiency for the administration of the organizer and the provision of facilities (classrooms or transportation).

Apart from the various benefits generated, both for students and educational institutions, found several assessments that are considered lacking of e-Learning as a concept, among others are a.) Reduced interaction between teachers and students or between students. This deficiency can have an impact on the delay in the formation of values in the learning and teaching process, b.) The e-Learning system is also sometimes considered a product of capitalism because it tends to neglect academic aspects and prioritize business aspects, c.) Students are faced with learning activities based on learning systems, unlike the case with traditional learning styles that train students in psychomotor and affective aspects, d.) Lack of workers who have skills in the field of the Internet and computer mastery. Example: teachers, especially in remote areas, are not familiar with the mechanism of the Internet so that the learning and teaching process is not conducive. This phenomenon is supported by the fact that not all places or regions provide Internet facilities (the majority are caused by lack of electricity, telephone, or computer) and adequate software (software costs are still relatively expensive at this time), e.) Through learning patterns e-Learning, students are required to learn the material without the presence and assistance of a mentor. This can cause lazy factors in students because they are not motivated properly.

\section{B. Artifical Intelligence}

The discussion on e-Learning is inseparable from the smart programs behind it. The smart program is Artificial Intelligence or commonly abbreviated with AI. AI technology is one part of computer science that makes it easy for humans to work. Today, computers are not only used for simple purposes but are expected to be able to do everything that humans can do. In general, AI is a science that is used to imitate the intelligence possessed by living things and is applied through machines with the aim of solving a problem. This understanding is supported by a variety of opinions from experts: 
- John McCarthy (1960): AI is a computer system that is formed to know and model human thought processes and design machines so that they can mimic human behavior.[6]

- Rolston (1988): AI is a computer-based solution to existing problems using applications such as human thought processes.[7]

- Teahan (2010): AI is the science of how to build a computer system that shows intelligence in various ways.[8]

According to Konar, besides being a science of computer systems, Artificial Intelligence is also a dynamic study because it covers the science of technology, machinery, algorithms, mathematics, and complex code systems [9]. To run a system with an artificial intelligence program, at least there are several methods applied in its use:

- Fuzzy Logic (FL), which is a technique used to adapt how living things can adjust conditions by providing flexible decisions. The application of fuzzy logic can be done for consideration of uncertain things.

- Evolutionary Computing (EC). This method applies concepts inspired by biological sciences such as population and mutation to produce the best problem solving.

- Machine Learning (ML) or machine learning is a technique replacing or imitating human behavior.

During its development, several applications of Artificial Intelligence in life include the following, as quoted by Idris [10]:

- Natural Language Processing, where users can communicate with computers using everyday language. Artificial intelligence learns how natural language is processed so that users can communicate with computers. The concentration of this science is the interaction between computers and natural language used by humans, namely how computers extract information from input in its natural form or produce output that is also in the form of natural language.

- Expert System or Expert System, namely the field of science that studies computers as a tool for storing knowledge of experts so that computers have the ability to solve problems by imitating the expertise possessed by experts. The application of this system makes it easy for ordinary people to solve complex problems. According to Turban [10], an expert system can be displayed with two environments, namely the development environment and the consultation environment (runtime). The development environment is used by ES builders to build components and incorporate knowledge into the knowledge base. The consultation environment is used by non-rooted users to gain expert knowledge and advice. This environment can be separated after the system is complete.
- Speech Recognition or Speech Recognition, which is technology that is able to read human voices into a command and be understood by computers, so this allows humans to communicate with computers using sound. Examples of speech recognition that has been widely applied at this time are virtual assistant applications on mobile phones or other devices that support these features, including Siri, Cortana, Google Now, and many others.

The ability to solve a problem is one way to measure the intelligence of a program in various contexts. Measurement of intelligence of a program aims to see the ability of artificial intelligence in helping humans. What is meant by this intelligence is the ability of programs to learn, understand and comprehend messages, respond quickly to commands, and can solve problems effectively. Some goals of artificial intelligence according to Winston and Prendergast [12] are:

- Making machines smarter

- Understanding intelligence

- Increasing the benefits of machines.

According to Kusumadewi, Artificial Intelligence has advantages when compared to intelligence possessed by humans [13], namely:

- Permanent: as long as the system and program are not changed, artificial intelligence will not change.

- Easier to reproduce and spread: easier to move data from one computer to another when compared to sharing knowledge from one human to another.

- Consistent: artificial intelligence is a consistent computer technology, whereas natural intelligence has a tendency to change.

- Can be documented: each activity carried out by artificial intelligence can be easily tracked while natural intelligence is difficult to reproduce

- Able to do work faster and better.

- The cost is cheaper than bringing in an expert.

\section{Application of Artificial Intelligence in E-Learning in Indonesia}

As reported, from 2017 Indonesia has been ranked 8th (eighth) for e-Learning learning on a mondial scope. The results of this research are in line with the Ministry of Research, Technology and Higher Education of the Republic of Indonesia (Kemenristekdikti) who have actively voiced policies, programs and views on Indonesia's readiness to face the 4th Globalization of Education and the 4th Industrial Revolution (RI 4.0) since the beginning of the year 2018.

The Procurement of Education Globalization and RI 4.0 is driven by the urgency of the government to produce a generation of Human Resources (HR) who are competent, innovative, and capable of optimally mastering a field or science. HR with these criteria is considered capable of contributing to national development and helping the process of improving the quality of life. The inclusion of the name of Indonesia in the category of Countries that are ready to carry out the 4th Industrial Revolution according to the report "The 
Preliminary 4IR Country Readiness Evaluation" increases Indonesia's focus on education infrastructure in the framework of preparing for the 4IR (The Fourth Industrial Revolution).

Nevertheless, the impact of the educational revolution felt by developing countries like Indonesia, especially in primitive parts or regions, is actually not too significant. This is often due to the relatively low level of competition in the education system in Indonesia. In addition, the stage of the education system in Indonesia still persists in understanding Education 1.0. Utilization of the growing Internet in Indonesia has also not been fully utilized because the majority is still channeled to sustain social activities compared to accessing the development of science and technology.

One of the prominent characteristics of Education 1.0 is that teachers function as the main source in science and technology. Unlike the case with the understanding of teachers in the perspective of Education 4.0; The teacher has the main function as a group leader (Team Leader) who collaborates with students in creating science and technology through the process of Internet-based learning resources or Artificial Intelligence Portals. In reality, the role of Artificial Intelligence (AI) is indeed inseparable from the corridors of online learning; so that in the successful implementation of eLearning in Indonesia, constructive changes are needed, one of which is AI technology.

The idea of creating virtual guides and facilitators (able to think, act, react, interact and respond and use verbal and nonverbal communication) to be used in educational settings such as e-Learning can be a promising development. Although not yet implemented in Indonesia, installation of AI technology in e-Learning systems has been implemented in several countries such as the United States. University of Southern California (USC) and the Captivating Virtual Instruction for Training (CVIT) project, for example. CVIT is a learning strategy that aims to integrate traditional methods (learning activities in class) with the most appropriate virtual technology (intelligent tutors, Augmented Reality (AR), etc.) in e-Learning programs.

The idea of a virtual facilitator is thought to be able to answer the problem of human resources in Indonesia in terms of quantity (the number of people's interest in the teaching profession is still low) and quality (as previously explained, there are still teachers who have not received maximum education related to the use and application of Internet technology and e-Learning). Not only that, the virtual facilitator's solution also addresses issues related to education culture in Indonesia that are familiar with learning and teaching activities in the classroom. Analog transition to digital certainly raises its own unrest for teachers and especially students. In this case, students are at risk of failing to adapt and result in rejection of the online learning system. Therefore, the emergence of virtual facilitators with humanlike characteristics is expected to be able to create real-time experiences, such as question and answer sessions and so on. E-Learning, too, can be done together collectively through video conferencing applications to further create the 'euphoria' of learning in the classroom.

In addition to making ideas in forming virtual guides and facilitators, the adoption of an adaptive learning environment also encourages the success rate of applying artificial intelligence to e-Learning in Indonesia. One example of e-
Learning products in Indonesia that implements adaptive learning environments and has been running for a long time is HarukaEdu. As quoted by Kompasiana, HarukaEdu is a wellknown online learning tool in maintaining quality, fixing the cost of proper education, and acting as a partner for individuals who have difficulty in accessing the internet. Besides lectures can be done remotely, users also get free online courses or training courses through collaboration with several universities in Indonesia.

Further discussion about Machine Learning and AI in eLearning is inseparable from the several advantages it can offer. The application of AI in e-Learning content opens up new ways of looking at learning itself. Everyone learns in different ways, and follows different steps, so that one of the main challenges in teaching and learning activities in general is to maintain a balance between involving students who are faster and accommodate those who are slower. AI in situations like this, creates an adaptive learning environment so that it allows the pace of learning to adjust to each individual. This includes environments that can accommodate individual learning styles and run in parallel, with each other. E-Learning content can also be adjusted based on past performance and learning objectives of each student so that each student can gradually collect the building blocks needed by their respective skills, for example: a student who completes the module faster will then be given material with an approach more comprehensive, whereas students who lack basic knowledge will be given linear modules. Thus, creating a learning environment that is far more effective and increases the likelihood of a group of individuals assimilating information accurately within a certain period of time.

Regardless of the quality of learning, AI presents a very valuable solution for e-Learning in the world of education with a high level of dynamics. E-Learning systems that need to update their subject matter continuously will benefit from an adaptive learning environment because Machine Learning has the ability to accurately predict how subject matter needs to be updated and changed, by analyzing data to be personalized. Adaptive learning technology will create an environment that is fully adapted to content that is not only changing but is also made based on the needs of students or individuals. Thus, the use of this technology will greatly improve the quality of education received by students. In addition, the application of the Machine Learning concept to e-Learning is closely related to the allocation of resources. With the lack of quantity and uneven human resources throughout Indonesia, in this case teachers, students who use e-Learning as a complement can receive the online resources they need to support learning materials, in accordance with their interests and academic goals. This personalization feature can also give students additional motivation and ease to reach their potential.

\section{Indonesian Readiness Against the Implementation of Artificial Intelligence in E-Learning}

E-learning is an interesting learning media because of the ease of accessing it that is not limited by time and place. Increasingly high user interest is faced by various obstacles in terms of infrastructure, resources, access to information, government support and policies, technological advances, and the culture of the people therein. In addition, the factors that move students towards e-Learning education also need to be carefully understood. Different student characteristics in each 
country certainly have their own way of responding to various knowledge-oriented initiatives. Therefore, studies of readiness for the application of Artificial Intelligence in eLearning must consider the specific influence on each situation, institution or learning program. Although various factors influence implementation and effectiveness, readiness is a critical success factor. In addition, the readiness of integration both involves many components including students, instructors, technology, and the environment, which must be prepared to formulate a coherent and achievable strategy. The level of readiness for implementing AI in eLearning can help education stakeholders to design and adjust resources, as well as direct the national government to formulate a comprehensive strategy for overcoming challenges and implementing objectives effectively.

Because e-Learning is a student-centered learning medium, the main focus is to shift learning activities in Indonesia from passive to active mode. Students become the core players in the e-Learning learning process, especially with the use of AI that requires the active role of its users in order to work optimally. Strengthening the learning model is needed through material enrichment and development of educational technology, so that there will be a shift in the role of the teacher who is no longer the main source of information, but rather the active role of students themselves (Education 4.0). At this time, Indonesia still needs technical training for teachers to get briefing and debriefing, so they can understand their role as facilitators, collaborators, mentors, trainers and study partners for students in the e-learning process.

In implementing $\mathrm{AI}$ in e-learning media, teachers as facilitators are required to have some basic competencies, namely: the ability to make instructional designs, learning according to pedagogical rules, and mastery of ICT, namely the use of the internet as a source of learning in order to obtain the latest and quality teaching material, and mastery of learning materials according to their expertise [14]. Various counseling, seminars, workshops, and technical guidance related to the application of e-Learning learning can be held in educational institutions, and also discussion forums through various media so that teachers can exchange ideas or experiences.

In addition, infrastructure in Indonesia is still inadequate in facilitating the needs of the latest AI technology. The government needs to improve facilities and infrastructure that support e-Learning learning to be effective. These components include the reach of electricity to the area, fast internet connection, and computers with the latest system provided at educational institutions. With infrastructure growth that is fast and increasingly optimal, the integration of AI in e-Learning will also be easier to apply, so that it will have an impact on improving the quality of education in Indonesia.

\section{CONCLUSION}

The era of globalization has a significant effect on the development sector, especially technology in Indonesia. Nowadays, technology and communication have a high degree of correlation in everyday life. In fact, technology is no longer a complementary device that is facultative but rather a primary need for humans and even solutions to overcome the central problems of a country. This information is clearly illustrated through the involvement of technology in the education system in Indonesia.

The arrival of e-Learning in 2003 marked the movement of the government to improve the education system in Indonesia. Until now e-Learning development has run consistently even though it has not reached the maximum point; so an escalation in technical terms is needed, such as integration with AI technology. The benefits of deep learning and its applications are considered capable of meeting the growing needs of e-Learning systems. However, every idea of transition will be faced with fundamental consequences. Therefore, appropriate and effective handling is needed.

Infrastructure is not only intended for the system alone, but in the mentality of users in planning the industrial revolution 4.0. Educational institutions are required to improve the quality of humans as users of technology to be applied in the education system and not just focus on the provision of information and communication technology. This suggestion arises on the basis of the essence of improving the quality of education not only in the sophistication of technology but also in the sophistication of educators and students in carrying out the educational process. The education sector in Indonesia is increasingly able to improve the quality of life of its population through collective adjustments and perfectly integrated systems.

\section{REFERENCES}

[1] Lukmana, Lukas. Dukungan Industri Software Dalam Implementasi ELearning di Dunia Pendidikan, 2006

[2] Masie, E., Kelly, K., \& MASIE Center. Conversations with Kevin Kelly and Elliott Masie. Saratoga Springs: MASIE Center Inc, 2000.

[3] Jenkins, M., \& LTSN Generic Centre, "LTSN generic centre e-learning series.” York: Learning and Teaching Support Network, 2003.

[4] Cross, J. A., Dublin, L., \& American Society for Training and Development, "Implementing e-learning," Alexandria: American Society for Training \& Development, 2002.

[5] Siahaan, Sudirman, "E-Learning (pembelajaran elektronik) sebagai salah satu alternatif kegiatan pembelajaran.” Jurnal Pendidikan dan Kebudayaan, 2002.

[6] McCarthy, John. Recursive functions of symbolic expressions and their computation by machine in Communications of the ACM. Academic, 1960

[7] H. Rolston, Environmental Ethics: Duties to and Values in the Natural World. Bormann, 1988

[8] W. J. Teahan, Artificial Intelligence - Agents and Environments. Bookboon, 2010

[9] A. Konar, Computational Intelligence: Principles, Techniques and Applications. Springer, 2002.

[10] Ismaila, Idris, Model and Algorithm, "Artificial immune system for spam detection," International Journal of Artificial Intelligence and Applications, vol. 4, 2012

[11] E. Turban, Decision Support and Expert Systems, Management Support Systems. Macmillan, 1990.

[12] P.H. Winston and K.A. Prendergast. The AI Business, The Commercial. Uses of Artificial Intelligence. The MIT Press, 1980.

[13] Kusumadewi, Sri. Artificial Intelligence (Teknik dan Aplikasinya). Graha Ilmu, 2003.

[14] Sulistyo-Basuki, L, "IT and education, the case study of e-learning in Indonesia," Information Revolution and Cultural Integration in East Asia, 2007.

[15] Soekartawi, "Prospects and challenges e-Learning: a review." UPSI, Tanjong Malim, 2003

[16] Antonius Aditya, Hartanto dan Onno W. Purbo, E-Learning berbasis PHP dan MySql. Elex Media Komputindo, 2002 